\title{
Repensando a história do karate contada no Brasil
}

CDD. 20.ed. 796.08

796.84

\author{
Tiago Oviedo FROSI* \\ J anice Zarpellon MAZO*
}

*Escola Superior de Educacão Física, Universidade Federal do Rio Grande do Sul.

\section{Resumo}

Este estudo aborda diversos aspectos presentes na literatura e que moldam o pensamento presente no imaginário dos brasileiros sobre a identidade, história e filosofia do Karate-Dō ${ }^{1} .0$ objetivo deste estudo é produzir uma meta análise da literatura circulante sobre a inserção e o desenvolvimento do Karate no Brasil, abordando seus diferentes estilos. Justifica-se este estudo pelo fato de considerarmos que foi difundida no Brasil uma versão distorcida sobre a história do Karate por meio da mídia, pela tradição oral e pelo preconceito entre os praticantes de diferentes estilos. As reflexões aqui apresentadas buscam contribuir com informações para a construção de outra versão sobre esta prática em nosso país.

UnITERMOS: Karate; História, Esporte.

\section{Considerações iniciais}

Este estudo aborda diversos aspectos presentes na literatura e que moldam o pensamento presente no imaginário dos brasileiros sobre a identidade, história e filosofia do Karate-Dō. Esta pesquisa se origina de uma profunda preocupação em relação aos equívocos presentes em sites da internet, manuais de associações, revistas e, com maior gravidade, em artigos, dissertaçôes e teses acadêmicas acerca dos aspectos teóricos que envolvem esta disciplina oriental. Estes últimos trabalhos, que deveriam ser a vanguarda do conhecimento histórico e técnico se apresentam como combustível para a fornalha dos tropeços acerca do Caminho das Mãos Vazias.

O objetivo deste estudo é produzir uma meta análise da literatura circulante sobre a inserção e o desenvolvimento do Karate no Brasil, abordando seus diferentes estilos. A perspectiva teórica adotada para tal foi a História Cultural (BURKE, 2008; PESAVENTO, 2008), pois nos permite uma leitura complexa, abordando as nuances da transmissão e transformação histórica da prática do Karate. Pretende-se, assim, por meio de categorias como práticas e representações, questionar a história do Karate no Brasil popularmente difundida, distinguindo o que se transmitiu através do seu imaginário próprio daquilo que são condições factuais para seu desenvolvimento.

Para a construção deste texto foram consultados livros escritos pelos mestres orientais, livros de professores brasileiros, artigos de revistas e jornais sobre o Karate no Brasil, dissertações e teses acadêmicas, além de documentários em DVDs ligados ao tema da pesquisa e obras sobre a história, filosofia e psicologia oriental, para aproximarmo-nos do objeto de estudo. Optou-se também por utilizar os sistemas de romanização Hepburn (He-bon Shiki Rōmaji) e Hànyǔ Pīnyīn dos termos nos idiomas: japonês (Nihongo), oquinauense (Uchināguchi) e chinês. Tal procedimento assegura o uso dos termos corretamente, possibilitando a análise etimológica dos ideogramas (Kanji e Kana) e a manutenção da representação gráfica da pronúncia original dos vocábulos (GOULART, 2009).

É fato que a maioria dos praticantes e professores não questiona os textos da obra de mestres como Gichin Funakoshi e Masatoshi Nakayama, considerados o pai do Karate moderno e o principal difusor mundial do Karate esportivo, respectivamente. Como a literatura revela, além de ignorar a história da maioria dos estilos de Karate (que compõe um universo de mais de 60 escolas diferentes), estes e praticamente todos os autores que os sucederam alimentam uma ideia centralizada no estilo Shōtōkan, ampliando-o no máximo para estilos contemporâneos a Funakoshi como Gōjū-ryū e Shitō-ryū ou a estilos como o Kyokushinkaikan que forçaram sua passagem, tanto política como competitivamente, no imaginário ligado ao Karate-Dō. 
Justifica-se este estudo por ser uma contribuição para os estudos históricos sobre o Karate-Dō, amplamente distorcida pela divulgação na mídia, pela tradição oral estabelecida no Brasil, que é muito diferente da tradição

\section{Revisando a história do karate}

Para entender o que é o Karate-Dō, vejo a necessidade de reconstruirmos suas origens históricas, bem como de suas técnicas. Para isso é preciso interpretar historicamente o Karate-Dō distinguindo as ideias do imaginário daquilo que as fontes nos apresentam como eventos ocorridos ao longo do processo de desenvolvimento desta prática. Preocupamo-nos, assim, em apontar aquelas crenças que são transmitidas oralmente nas academias e outros espaços de prática do Karate, mas que não se sustentam pelas evidências empíricas (no caso, as fontes históricas) nem pela "teoria" que embasa a formação do praticante de Karate (os princípios do Budō, amplamente difundidos por mestres como Gichin Funakoshi), o que nos remete a não podermos considerar estas crenças como Conhecimento (GAYA, 2008). Entre estas crenças, podemos citar as ideias de que o Karate surgiu a partir das práticas de imitar animais, de indianos que ensinaram os shaolin, que por sua vez instruíram algum pirata que se escondeu em Okinawa, o qual por sua vez deu o nome de Karate a essa arte. Também devemos recusar a teoria que sustenta que o Karate-Dō é proveniente do Jiu-Jítsu (em japonês Jūjutsu²). Há uma corrente no imaginário, identificada por TAN (2004) que pretendia até mesmo afirmar que determinados membros da realeza de Okinawa fossem de origem japonesa, o que possibilitaria essa conexão com uma origem japonesa e uma origem técnica no Jū-jutsu. Os estudos deste autor, enfim, refutaram esta teoria. Na verdade, essas histórias têm pouco, ou nada a responder sobre as origens do Karate-Dō. oral do japonês, e pelo preconceito entre os praticantes de determinados estilos para com os praticantes dos outros estilos. Vale a ressalva que este fenômeno não é unicamente brasileiro, mas é muito forte em nosso país.

\section{A China, os Peichin e o misterioso Tō-de}

O Karate-Dō tem sua origem em um extenso processo multicultural. Isto é evidenciado pelo conflito de identidades ao longo de sua própria história e a falta de reconhecimento deste como arte marcial nacional pelos japoneses até hoje (ANDRETTA, 2009; TAZAWA, 1980). A origem, em geral, das artes marciais é apontada através da introdução de práticas pelo monge indiano Ta Mo Lao Tse, o Bodhi Dharma ${ }^{3}$, no mosteiro Shaolin ${ }^{4}$ (na China), por volta da década de 520 da Era Cristã (Reid \& Croucher, 2004). Porém o caso do Karate é muito mais específico. Como diversos pequenos reinos do século XIV, Ryūkyū ${ }^{5}$ (o arquipélago ao sul do Japão e a leste da China, da qual Okinawa $^{6}$ era a Ilha principal) era um estado vassalo ao Império Chinês, desde o século XIII ou XIV (Camps \& Cerezo, 2005; Nakazato, Oshiro, Miyagi, Tuha, Kohagura, Higaonna, Taira \& SAKUMOTO, 2003; YAMASHIRO, 1993).

Nessa época, o reino adotava um sistema de castas sociais muito semelhantes ao dos grandes países da região: China, Índia e Japão (QUADRO 1), e excluía a vida entre os nobres, o clero, os militares e os camponeses (FunAKOSHI, 1999; RATTI \& WesтвROOK, 2006). Os Heimin ${ }^{7}$ (termo japonês para camponeses) do Ryūkyū viviam numa situação nada agradável, pois, a exemplo do que acontecia em muitos feudos nipônicos, acabavam por pagar com quase todo o produto da colheita, os 'tributos reais' que eram exigidos pela aristocracia.

QUADRO1-Castas do reino de Ryūkyū no período feudal (Adaptado de ANDRETTA, 2009).

\begin{tabular}{|l|l|l|}
\hline Aristocracia/Realeza & Guerreiros & Plebeus \\
\hline Família Shō [尚] & Peichin [亲云上] & \\
\hline Oji [王子] - Rei & Pēkumī [亲云上] - Peichin de nível alto & \\
\hline $\begin{array}{l}\text { Aji ou Anji [按司] - Descendentes do } \\
\text { rei, membros da Família Real }\end{array}$ & $\begin{array}{l}\text { Satunushi Peichin [里之子亲云上] - } \\
\text { Peichin de nível médio }\end{array}$ & Heimin [平民] \\
\hline $\begin{array}{l}\text { Uēkata ou Oyakata [亲方] - Senhor } \\
\text { (feudal) }\end{array}$ & $\begin{array}{l}\text { Chikudun Peichin [筑登之亲云上] - } \\
\text { Peichin de nível baixo }\end{array}$ & \\
\hline Tonochi - Senhor de pequeno feudo & & \\
\hline
\end{tabular}


Pior do que não ter o que comer, eles (os Heimin) tinham um problema social a suportar que era, provavelmente, pior que a fome: a truculência impiedosa dos Peichin ${ }^{8}$, os membros da casta guerreira, militares semelhantes aos samurai japoneses (SHINZATO \& BuENO, 2007). Estes guerreiros tinham, entre outras funções, cobrar os tributos, geralmente uma gorda parcela do arroz produzido pelos camponeses. Como não se podia impedir o efeito das intempéries ${ }^{10}$, por vez ou outra os Heimin acabavam por perder toda ou boa parte da colheita, detalhe que não interessava aos Peichin. Muitos foram os camponeses que partiram para o trabalho na lavoura e após um dia estafante de trabalho árduo retornaram apenas para encontrar suas casas incendiadas e suas famílias mutiladas e empaladas sob o poente das ilhas do Ryūkyū, o castigo governamental pela inadimplência (RATTI \& WESTBROOK, 2006). Esta situação acabou estimulando os agricultores a criarem formas de se exercitar e se preparar para os embates com os Peichin.

Como o porte de armas pela população comum era proibido pelos reis da Dinastia Shō, os Heimin passaram a sistematizar dois sistemas de defesa pessoal que, em verdade, eram treinados juntos. A estes chamaram genericamente de $T e^{11}$ (ou $T i$ na antiga pronúncia do dialeto de Okinawa ${ }^{12}$ ), cujas formas eram rudimentares em relação ao que viríamos conhecer por Karate-Dō e Kobu-Dō de Okinawa (ShinZato \& Bueno, 2007). Empregaram contra os Peichin, técnicas toscas de agarramento, empurrões, batidas de ombro, punho e pé, além do uso de ferramentas rurais como os batedores de arroz, varas, enxadas, foices, linhas de pesca, manivelas de moinho, ancinhos e outros, para se proteger das espadas, correntes e lanças dos guerreiros do Rei. Outro fator apontado para uma nova onda de desenvolvimento do $T e$ foi um segundo decreto de proibição do porte de armas pelos ocupantes japoneses de Okinawa em 1609, o clã samurai Shimazu ${ }^{13}$ de Satsuma de Kyushu (Nakazato et al., 2003).

A partir do século XVII, houve a apropriação do Te pelos guerreiros de Okinawa (Peichin), que passaram a realizar vários intercâmbios com marinheiros e militares chineses com quem viriam a aprender as artes marciais daquele país e passariam a desenvolver a arte que chamariam de Tō-de ${ }^{14}$ (no dialeto de Okinawa, e Karate ${ }^{15}$ em japonês). $\mathrm{O}$ arquipélago era então uma região privilegiada pela localização, pois servia de rota comercial/marítima para as embarcações chinesas que queriam comercializar com o Japão e vice-versa (FUNAKOSHI, 1999; YAMASHIRO, 1993).
Desde 1404 d.C., os Ryūkyū recebiam visitas 'diplomáticas' de representantes chineses, pois como já citamos o reino do qual Okinawa fazia parte era vassalo deste país. Nessas visitas (dos Sapposhicin) comumente seus integrantes eram militares do 'país do meio' que vinham supervisionar as relações entre Ryūkyū e a China. Passados 25 anos do primeiro encontro, Shō Hashi unificaria os reinos dos Ryūkyū, estabelecendo, entre outras coisas, a periodicidade da vinda dos Sapposhi. Sabe-se que esses eventos eram momentos importantes para trocas culturais com os representantes chineses e que, na vinda do Sapposhi de 1756 d.C. (o $19^{\circ}$, sob liderança do embaixador Zenkai), foram realizadas demonstrações dos especialistas Kūshankū ${ }^{17}$ (Kung Sian Chung ou Gong Xiang Jun), Peichin Sakugawa e Chatan Yara, introduzindo respectivamente as técnicas dos sistemas chamados então: Kūshankū-zaiko, Tō-de Sakugawa e Chatan Yara no Kenpōis (NAKAZATO et al., 2003).

Porém, o que ocorria era que, nesta época, alguns Peichin como Sanga Sakugawa já haviam se apropriado das técnicas de luta locais, o Te de Okinawa. Depois de passar por situações difíceis para conter os Heimin revoltosos desde o século XV, os guerreiros oquinauenses passaram a estudar a luta de mãos nuas nativa, chegando a criar um sistema de graduação de seis hachimaki (faixas de testa) coloridos, a exemplo das faixas que são usadas atualmente na cintura para graduações de Kyū. Foram, portanto, os membros da casta guerreira de Okinawa aqueles que realmente impulsionaram o desenvolvimento do Karate-Dō (Shinzato \& Bueno, 2007).

A influência crucial das artes chinesas nas técnicas locais pode ser constatada através dos manuscritos chamados Bubishi. Este Tratado de Preparação Guerreira foi sendo copiado manualmente por gerações, até ser formalmente documentado nas Notas de Oshima por Ryosho Tobe. Neste documento, além do Bubishi, Tobe transcreveu o Kūshankū, tratado sobre as técnicas do militar chinês Kung Siang Chun, e o Kumiaijutsu (NAKAZATO et al., 2003). Na parte que competia ao Kūshankū, Tobe apresenta as técnicas que deram origem aos Kata que conhecemos hoje por Kūshankū, Kōsōkun ${ }^{19}$ ou Kankū ${ }^{20}$. No trecho que apresenta o Bubishi, podemos ver as chamadas 48 técnicas de Quan, onde dois guerreiros com vestimentas chinesas combatem. Aliás, com admirável semelhança à representação artística do famoso quadro sobre os monges do mosteiro Shaolin, até hoje conservado na China (Reid \& Croucher, 2004).

As incríveis histórias envolvendo diversos guerreiros de Okinawa praticantes do Tō-de tais como 
Sōkon Matsumura ${ }^{21}$, Kishin Teruya, Kōsaku Matsumora, Ankō Itosu ${ }^{22}$ e Kanryō Higaonna ${ }^{23}$ fizeram com que a arte fosse chamada por nomes como Shimpi Tō-de ${ }^{24}$ ou Reimyō Tō-de ${ }^{25}$ (HigaOnNA, 1986; NAKAYAMA, 2000). Aqueles feitos inconcebíveis, como a capacidade de receber inúmeros golpes sem sofrer danos, paralisar adversários com o ki-ai ${ }^{26}$, romper troncos de árvores com golpes ou esmagar grossos talos de bambu com as mãos nuas, vem sendo estudados como movimentos das energias do corpo vital pela nova área de estudos sobre a consciência (Goswami, ReEd \& Goswami, 2008; Laszlo, 2008).

\section{A Perpetuação nas famílias e o karate nas escolas}

No tempo do Tō-de moderno, o século XIX, iniciava em Okinawa os treinos dos mestres mais conhecidos por levar a arte ao Japão Continental. Acabava assim, a cultura do Isshi-soden, ou seja, a passagem das técnicas de defesa pessoal apenas entre parentes e iniciava a prática do Karate nas escolas de Okinawa. Neste contexto, dentro da classe guerreira de Okinawa, os Peichin, havia uma regra peculiar: passar os conhecimentos do Tō-de da família secretamente apenas para o primogênito. Esse costume, ou regra, era chamado Ishi-soden, e é a ele que Gichin Funakoshi ${ }^{27}$ (1999, 2000) e outros autores se referem quando falam sobre a passagem das técnicas do Karate primitivo de forma secreta. Alguns Peichin como Sanga Sakugawa e Sōkon Matsumura estudaram $W u-s h u^{28}$ na China e as trouxeram para unir estes conhecimentos ao $T e$, formulando assim o Tō-de. Não teriam eles criado esta regra de transmissão individual? Se pensarmos que as verdadeiras gangues de boxers nas quais muitas escolas de Wu-shu eram transformadas (REID \& Croucher, 2004), não é de se admirar que o Isshisoden tenha sido uma medida preventiva para que isso não acontecesse nos Ryūkyū.

Praticava-se então, durante os dois séculos seguintes, três linhas de Tō-de nominadas de acordo com a localidade onde foram originadas (as cidades de Shuri, Naha e Tomari). Eram as linhas Shuri-Te $e^{29}$, Naha-Te ${ }^{30}$ e Tomari-Te ${ }^{31}$, que enfatizavam potência muscular, respiração e ritmo dos movimentos respectivamente (NAKAZATO et al., 2003).

A partir da restauração Meiji ${ }^{32}$ de 1868 , e das diversas transformações sociais que ocorreram no período, principalmente o abandono dos costumes oriundos do período feudal controlado pelo Xogunato, o Isshi-soden foi abolido e passou a haver menos controle sobre a prática do Tō-de, que podia então ser ensinado não apenas a um aluno, mas a um pequeno número de alunos. Surgiu nesta época o costume de se 'entregar' a criação (ou pelo menos o treinamento em Tō-de) do filho para um amigo da família (FunAKOSHI, 2000).

Nesta época, um dos mais eminentes mestres da arte de Okinawa passou a trabalhar em uma forma de levar a prática do Karate ao público geral, tornando-o a disciplina de Educação Física nas escolas. Para isto, Ankō Itosu (ou Yasutsune Itosu em algumas traduçōes) formulou os "Dez artigos sobre o Tō-de", que bem aceitos pelos dirigentes do sistema educacional da época possibilitaram a inserção do Karate nas escolas da prefeitura de Okinawa (FunAKOSHI, 2000).

Sabe-se que o próprio mestre Gichin Funakoshi aproveitou a oportunidade, já que fora educado nos clássicos chineses (Daikyō, Chukyō e Shōkyō) e outras obras importantes da época por seus avôs, também professores de literatura e caligrafia ${ }^{33}$, para tornar-se professor. Muitos pontos interessantes relacionados a esse fato, como a resistência de seu pai, que Funakoshi descreve como um descendente de samurai (no caso, provavelmente de Peichin) e o fato de Funakoshi ter recusado-se a ingressar na Faculdade de Medicina de uma das principais universidades japonesas para não ser obrigado a cortar o birote (nó de cabelo samurai que usava, e que fora proibido pela política da restauração Meiji, entre outros costumes dos antigos guerreiros). Podemos ver como diversas mudanças sócio-culturais naquela sociedade influenciaram a vida e os costumes das pessoas, através do relato do mestre em seus livros (FunAKOSHI, 1999, 2000). Outros grandes mestres da época, como Jigorō Kanō (o fundador do Jūdōo ${ }^{34}$ ), também escolheram atuar como professores, o que era muito vantajoso no período, pois o novo regime (Meiji) transformara esta profissão numa das mais respeitadas e rentáveis do final do século XIX e início do século XX (STEVEns, 2005).

Da mesma forma que no Japão continental se usava o jargão: a educação que antes era direito único dos samurai agora será para todos os membros do povo (RATTI \& WestbROOK, 2006), para conquistar o apoio popular, em Okinawa se procedia de forma semelhante. O fim do Isshi-soden e a introdução do Tō-de nas escolas municipais foi uma forma de ganhar o povo pelo fim do segredo dos Peichin e ganhar as autoridades pela possibilidade de promover uma educação guerreira desde a infância (a ideia principal da carta de Itosu - Os Dez Artigos sobre 
Tō-de - aos dirigentes do sistema educacional). Foi uma medida diretamente ligada a uma cultura de fortalecimento militar do Japão (do qual Okinawa já fazia parte totalmente) que se preparava para um embate com a Rússia (FunaKoshi, 1999).

Por fim, essa abertura cultural e o próprio desenvolvimento do Karate tomariam um caminho sem volta em direção a expansão para o Japão continental e para o mundo. A partir da década de 20, diversos mestres de Okinawa iriam para o Japão a fim de disseminar a arte que vinha sendo cultivada há séculos pelos Peichin. Era o cenário da transição das "Mãos Chinesas" para o "Caminho das Mãos Vazias".

\section{Karate-Dō: do Japão para o Mundo}

Em 1921, numa viagem do Príncipe Hirohito, a comitiva imperial acabou fazendo uma breve parada em Okinawa. Para receber o futuro Imperador, os habitantes de Okinawa prepararam uma grande recepção, onde, entre as atividades, estava prevista uma apresentação de Tō-de (FunAKOSHI, 1999). Neste episódio, Gichin Funakoshi estava presente com seus alunos da escola municipal, deslumbrando o jovem príncipe com uma demonstração de Embu (luta combinada entre dois ou mais karate- $k a^{35}$, uma espécie de coreografia).

As ótimas impressões causadas pela apresentação renderam aos oquinauenses um convite para demonstrar o Tō-de no Japão continental, na ' 1 a Exibição Atlética Nacional', evento promovido pelo Ministério da Educação do país (NAKAZATO et al., 2003). Naquela oportunidade, Funakoshi e seu grupo foram à Tóquio realizar uma nova demonstração para diversas autoridades japonesas e para o grande público. Curioso, no episódio, foram os uniformes: hachimaki e camisetas (sim! "T-shirts" ocidentais!) brancas (apenas Funakoshi usou um uwagi $i^{36}$ branco), hakama ${ }^{37}$ pretos compridos até metade das pernas (que no período feudal designava os guerreiros de classe mediana) e longos bo (bastóes de madeira usados nas artes marciais japonesas).

Daí em diante, Funakoshi não conseguiu mais retornar à Okinawa, sendo diversas vezes persuadido por vários grupos a permanecer no Japão ensinando Karate. Até no Instituto Kōdōkan, fundado por Jigorō Kanō, Funakoshi-Sense ${ }^{38}$ permaneceu ensinando a pedido deste (Stevens, 2005). Publicou ainda em 1922 seu primeiro livro: Ryūkyū Kenpō: Karate. Promoveu assim a mudança dos ideogramas que formavam a palavra Karate ${ }^{39}$ (em japonês, a pronúncia dos ideogramas para Tō-de é Karate, como explicado anteriormente), que significavam "Mãos chinesas", para Karate $e^{40}$ significando "Mãos vazias" (FuNAKOSHI, 1973). Buscava assim uma desvinculação ao país rival militar do Japão e se aproximando, assim, do Império nipônico (FunAKOSHI, 1999). No processo de buscar o reconhecimento do Karate como arte marcial pelos japoneses, mestre Funakoshi ainda incluiu o ideograma $D^{0}{ }^{41}$ ao nome, adotou o sistema de graduação kyū/dan e o uniforme, ou dōgíí ${ }^{42}$, ambos criados por Jigorō Kanō.

Alguns anos depois, um fato acabaria estremecendo as relações entre dois grandes mestres do período: Gichin Funakoshi e Chōki Motobu ${ }^{43}$. Muitas lendas surgiram em torno de um episódio, onde Motobu teria derrotado um lutador russo que estava a desafiar e vencer diversos peritos em Jū-jutsu e outras artes japonesas em Tóquio. O que se sabe é que Motobu, já estabelecido no Japão Continental, aproveitando a onda de popularidade do Karate iniciada por Funakoshi e a falta de instrutores de Karate que suprissem essa demanda acabou derrotando o lutador que entre outras coisas demonstrava técnicas do $S a m b o^{44}$, entortava barras de ferro no pescoço, etc. $\mathrm{O}$ acontecido conferiu grande fama à Motobu que passou a atrair muitos alunos (Ross, 2009).

O problema se deu quando a "King Magazine" publicou ilustrações de Funakoshi, e não Motobu, derrotando o russo. Chōki suspeitou que Funakoshi fosse o mentor da alteração e teve grandes atritos com o fundador do Shōtōkan ${ }^{45}$. De fato, em um de seus livros (Karate-Dō Nyūmon), Funakoshi afirma que em solo japonês só reconhecia outros dois estilos de Karate: o Gōjū-ryū ${ }^{46}$ de Sensei Miyagi e o Shitōryū ${ }^{47}$ de Sensei Mabuni (Funakoshi, 1999). No fim, era uma clara repulsa ao grupo de Motobu.

A partir daí diversos mestres de Okinawa vieram ao Japão continental ensinar a arte e uma explosão do Karate aconteceu no país. Passados cerca de 20 anos da primeira exibição atlética onde o Karate surge para os nipônicos, se iniciava um processo de modernização que buscaria aproximá-lo de práticas como o Jūdō e o Kendō ${ }^{48}$, as quais já possuíam sistemas competitivos e eram amplamente praticadas em escolas em todo país (Augusto, 2009). Apesar disso, o Karate sofreria um forte abalo, junto com tantas outras estruturas do Japão, devido aos acontecimentos da Segunda Guerra Mundial que assolaram todo o país.

A partir da década de 30, Gichin Funakoshi empreendeu diversas reformas e conseguiu abertura e aceitação do Karate no Japão, e diversos especialistas de Okinawa partiram ao Japão continental para ajudar na difusão da prática. Pelo seu trabalho incansável e grande disposição, Funakoshi conseguiu 
inclusive forjar amizades com pessoas como Jigorō $K{ }^{2}{ }^{49}$ e Morihei Ueshiba ${ }^{50}$, tendo este último inclusive aceito Shigeru Egami, um dos principais alunos de Funakoshi, para receber lições especiais (STEVENS, 2005). Neste período as belas apresentações de Karate organizadas por Funakoshi-Sensei tinham a participação de figuras como Kenwa Mabuni e Chōjun Miyagi (Aguiar, 2008).

É sabido de alguns movimentos desde a década de 40 para que o Karate se voltasse para uma forma competitiva a exemplo do que ocorria com Kendō e Jūdō, o que era desestimulado por Funakoshi e vários outros mestres da época. Mesmo assim, alguns alunos de Funakoshi passaram a praticar o que chamaram Jiyū Kumite (Disputa Livre) e há registro de alguns duelos a partir daí (Augusto, 2009). Antes disso, Hironori Otsuka ${ }^{51}$ já havia abandonado a escola de Funakoshi para dar sua própria interpretação a várias técnicas e unir com seus conhecimentos em Karate o que já sabia de Jū-jutsu.

A Segunda Guerra Mundial trouxe consequências catastróficas para o Karate. A ilha de Okinawa, cenário de uma das batalhas mais ferozes da guerra, foi arrasada e documentos e objetos foram destruídos, apagando parte dos vestígios da história de Okinawa e do próprio Karate (NAKAYAMA, 2004). Os bombardeios e combates no Japão continental também trouxeram consequências, como a destruição do Shōtōkan Dōjō, o prédio onde Funakoshi ministrava aulas e o falecimento do seu filho e braço direito, Gigo. Gigo, fragilizado pela alimentação com a ração dada ao povo pelo exército americano contraiu tuberculose e deixou o pai sozinho na estruturação do estilo.

Como se não bastassem as inúmeras adversidades, um decreto de proibição das artes marciais foi outorgado pelo exército americano (ReID \& Croucher, 2004). Curiosamente, a única arte que não foi proibida neste decreto foi o Karate (REID \& Croucher, 2004; Nakayama, 2000), pois após as observações dos militares dos Estados Unidos foi considerado apenas um jogo ou diversão local. $\mathrm{Na}$ verdade, algo semelhante ao que os negros fizeram para ocultar a capoeira no Brasil foi feito pelos oquinauenses. Eles associaram a prática dos Kata (exercícios formais) a uma dança com tambores, apitos e movimentos enérgicos própria de Okinawa, o Senbaru Eisa (OKInAWA, 2003).

No final da década de 50, quando faleceu o mestre Funakoshi, um triste fato ocorreu, mas foi camuflado pela maioria dos praticantes do KarateDō. Houve uma disputa entre os dois segmentos de discípulos do mestre, que seguiam caminhos bastante diferentes desde a morte de $\mathrm{Gigo}^{52}$, no pós-guerra. Os karate-ka da Shōtōkai, liderados por mestre Egami defendiam que o enterro de Funakoshi Sensei deveria ser realizado pela sua família, enquanto os membros da Japan Karate Association (JKA), liderados por Masatoshi Nakayama, queriam que o enterro fosse realizado por esta associação em grande solenidade (Egami, 2000). Como a disputa acabou com a vitória do lado de Egami, Nakayama e seus seguidores não compareceram ao enterro, o que causou revolta e inimizades no mundo do Karate, principalmente dos seguidores de Egami.

Com todas as turbulências que ocorriam, porém, a difusão do Karate pelo mundo era inevitável. Diversos militares ocidentais, que participavam da ocupação do Japão desde a Segunda Guerra Mundial, tiveram lições da arte das mãos vazias no período em que participaram das empreitadas bélicas e, ao regressar às suas terras, passavam a ensinar o que aprenderam (CHAMbers \& DufF, 2008; Shinjyo, Senaha \& Onaga, 2004). Para evitar que a arte fosse disseminada com aspectos técnicos e filosóficos distorcidos dos originais, vários mestres do Japão e de Okinawa passaram a se encaminhar para países da Europa e América, principalmente, para trabalhar no movimento de expansão do Karate ${ }^{53}$. Em 1934, o próprio Chōjun Miyagi foi ao Havaí promover a difusão do Gōjūryū, aproveitando a oportunidade em que sua família abria negócios na localidade, sendo um dos primeiros a sair do Japão para tal feito (NAKAZATO et al., 2003). Mestres da JKA rumaram para a Europa a fim de promover a difusão do Karate, entre estes, os principais foram: Sensei Kawasoe, Sensei Enoeda, Sensei Taiji Kase, Sensei Hiroshi Shirai, Sensei Tomita, Sensei Hidetaka Nishiyama e Sensei Hirokazu Kanazawa (GonelLA, 2003).

No período que sucedeu a Guerra Fria ocorreram grandes evoluções na organização do Karate mundial, havendo a fundação da Federação Europeia de Karate (UEK) em 1965, seguida por outras federaçôes continentais, à própria World Union of Karate Organization (WUKO) e organizaçôes que pretendiam liderar o Karate mundialmente, como a International Traditional Karate Federation (ITKF). Com a expansão das práticas e o ganho do mercado sucedeu-se um imenso espírito de rivalidade entre escolas e estilos, que perduraria até os acontecimentos que resultariam no reconhecimento da World Karate Federation (WKF) pelo Comitê Olímpico Internacional e na opção do Kyokushinkai ${ }^{54}$ de tornar-se esporte de contato (JKF, 2008). 


\section{O Karate na sociedade da informação}

$\mathrm{Na}$ década de 90 muitas mudanças tomaram o campo organizacional do Karate-Dō como esporte, sendo que até 1996 havia duas federações internacionais, a União Mundial das Organizaçōes de Karate (WUKO) e a Federação Internacional de Karate Tradicional (ITKF), com poder e representatividade equiparadas. Isto trazia problemas para que esta prática esportiva fosse reconhecida pelo Comitê Olímpico Internacional (COI) como esporte olímpico, o que repercutia também nos países no que diz respeito à difusão do Karate. Com a fusão da WUKO e da ITKF, surge em 1996 a Federação Mundial de Karate (WKF), favorecendo, então, o reconhecimento do Karate pelo COI, que aconteceria em 1999 (WKF, 2007).

A partir da influência do COI sobre o Karate, começaram a ocorrer diversas mudanças nas regras de competição, que foram tornando-o menos violento e possibilitando a diminuição do número de lesões, e também da gravidade das mesmas, nas competições e treinamentos (MaCAN, BundaloVRBANAC \& Romi'c, 2006). Desta forma, o Karate no Brasil passou a se orientar por essas diretrizes e também se modificou, como ocorreu nos demais países (Confederaçāo Brasileira de Karate, 2009). Nesta perspectiva, o caráter dessa prática relacionado inicialmente à defesa pessoal (arte marcial) sofreu uma ruptura através da mudança das regras de competição, buscando uma aproximação maior com o modelo de esporte olímpico (ESPERANÇA, 2003).

Apesar destas mudanças, houve muita resistência e alguns elementos da prática tradicional do Karate permaneceram e foram fomentados em competiçōes esportivas. No entanto, em janeiro de 2009, o Karate sofreu um golpe drástico em suas regras, pois certos elementos exigidos pelo COI foram adotados mesmo sob protesto dos defensores de uma prática mais tradicional. O Karate se configurou, assim, em uma manifestação cultural de nossa atualidade com uma faceta esportiva administrada pela WKF, onde há competições em todas as partes do mundo com regras uniformizadas, uso de protetores e a prática de exercícios formais pelos atletas que antes eram permitidos a poucos mestres de graduação avançada, mas também se apresenta de outras formas. Há as vertentes competitivas de práticas de maior contato, como o Karate Kyokushinkaikan e outras formas de Karate de Contato (Lowe, 1967; Oyama, 1980). Há escolas tradicionais que visam a defesa pessoal e o desenvolvimento filosófico/espiritual de forma semelhante à de tempos passados. Há também práticas voltadas ao espetáculo de forma mais explícita, como o Karate Artístico e formais transcendentais, que chegam a se aproximar muito do Aikidō e da Yoga, como o Karate Shōtōkai e o Shintai-dō.

A história da introdução do Karate no Brasil está diretamente ligada aos imigrantes japoneses que aqui se estabeleceram após a Segunda Guerra Mundial. Com a formação da colônia japonesa em São Paulo a partir de 1955 foi estabelecida a primeira academia de Karate naquela cidade, pelo sensei Mitsusuke Harada do estilo Shōtōkan (BARTOlo, 2009; CBK, 2009). Em 1959, o sensei Seiichi Akamine fundou a primeira academia do estilo Gōjū-ryū e em 1960 fundou a Associação Brasileira de Karate, e que mais tarde daria origem à Confederação Brasileira responsável pela administração do esporte (Oliveira, Millen Neto \& Jordāo, 2005). Neste ano outros conhecidos mestres, oriundos também da colônia japonesa de São Paulo praticavam a arte em solo nacional, eram eles: Juichi Sagara, Yasutaka Tanaka, Tetsuma Higashino e Sadamu Uriu.

Em 1961 o Karate foi introduzido na Bahia pelo sensei Eisuke Oishi, levado ao Estado pelo Dr. Angelo Decaino. No ano seguinte, o estilo Shorin-ryū, um dos mais tradicionais em Okinawa, era trazido ao país pelo sensei Yoshihide Shinzato, considerado também o pai do Kobu-Dō de Okinawa em solo brasileiro. Estes mestres foram, portanto, os introdutores do Caminho das Mãos Vazias no Brasil, em um processo de estruturação que levou cerca de 10 anos, aproximadamente de meados da década de 50 a meados da década de 60 , e propiciou a introdução da arte no território nacional. Há diversos problemas políticos, onde grupos isolados pretendem validar a este ou aquele mestre a introdução oficial do Karate, o primeiro de muitos equívocos que podemos citar. Independente do trabalho de um sensei ou outro, as datas e registros amplamente divulgados não deixam dúvidas sobre a identidade dos pioneiros e nos convidam a sairmos do círculo vicioso de difusão de informações distorcidas acerca da introdução, difusão e desenvolvimento do Karate em nosso país. Lembramos ainda, de forma justa, o trabalho de outros mestres que colaboraram para o desenvolvimento do Karate brasileiro, sendo estes: Milton Osaka, Hironasu Yoki, Benedito Nelson Augusto Santos (o primeiro faixa-preta não nissei do Brasil), Denislon Caribé, Lirton Monassa, Ailton Menezes, Oswaldo Duncan, Raimundo Bastos, Márcio Bienvenutti, Claudio Trigo, William Felippe, Julio Takuo Arai, Koji Takamatsu (Wadō-ryū), Taeto Okuda, Yoshizo Machida, Yasunori Yonamine, Akio Yokoyama, Michizo Buyo, Akira Taniguchi e Seiji Isobe (Kyokushinkaikan) (BARTOLO, 2009; PETTini, 2005). 


\section{Analisando alguns equívocos}

Primeiramente é necessário expor um ponto presente na maioria dos textos sobre o Karate: a definição de suas origens. Na quase totalidade dos textos, os autores afirmam que as origens da arte são misteriosas, turvas, desconhecidas ou remotas. Isso não se sustenta quando empreendemos uma simples pesquisa de internet. Rapidamente descobrimos que, além de um departamento de pesquisa histórica, mantido pela Prefeitura de Okinawa, que visa recuperar a memória de suas atividades e práticas culturais semidestruídas pelas batalhas da Segunda Guerra Mundial, há livros de importantes mestres de Okinawa contando fatos e lendas sobre a prática do Caminho das Mãos Vazias, desde próximo a sua sistematização nos Ryūkyū. Todo este material está disponível para aquele que tiver um mínimo de conhecimento para a leitura em língua inglesa.

Agora vamos abordar a questão da tradição oral. É comum relacionar o advento da escrita à civilização ocidental, vinculando a passagem das tradiçôes orientais predominantemente pela oralidade. Isso realmente acontece em alguns povos como os aborígenes australianos, pois sua visão de mundo implica uma desvalorização da via escrita (KNIGHT \& LOMAS, 2006). Porém, essa não era uma ideia compactuada pelos japoneses e oquinauenses. De fato, tanto os Bushi (guerreiros japoneses) quanto os Peichin (guerreiros de Ryūkyū) valorizavam a passagem de seus rituais, tradiçôes e técnicas diversas pela escrita. Ocorriam verdadeiras guerras no período feudal para que um clã $\left(U j i^{55}\right)$ se apoderasse dos Komonjo (rolos de papiro contendo a descrição escrita de técnicas secretas) de outros grupos ou famílias (RATTI \& WESTBROOK, 2006). Portanto, é importante entender que não é uma questão de tradição que a passagem dos conhecimentos do Karate no Brasil tenha acontecido de forma oral, e sim devido ao contexto estabelecido.

A própria entrevista com o mestre Yasutaka Tanaka apresentada por VIANNA (1996) é uma evidência potencial: o fato é que os mestres japoneses estabelecidos no nosso país não conseguiam se comunicar adequadamente em língua portuguesa para explicar conceitos filosóficos complexos oriundos de princípios monistas do Taoismo e do Budismo (Paranhos, 1994). Esses conceitos, como Zanshinn ${ }^{56}$, a atitude natural, em consonância com a Totalidade, ou $D o^{57}$; o $\operatorname{Hara}^{58}$ (o centro de poder do ser humano, equivalente ao core, ou coração, ocidental; e o Mushin ${ }^{59}$, a mente vazia, que proporciona o Zanshin muito bem explicada pelo psiquiatra Keneth KUSHNER (1988), influenciaram o desenvolvimento do Karate tanto quanto os princípios chineses de $W u$ Wei (atitude natural) e Wujin (mente vazia que proporciona o $W u$ Wei, Wujin é equivalente a Mushin), elucidada pelo psicólogo Paulo Blóise (2000) em sua dissertação. Devido à dificuldade de transmissão desse conhecimento pelos imigrantes japoneses, o que pode ser confirmada pelas diversas entrevistas com o mestre Shinzo Machida disponíveis na internet devido ao recente sucesso de seu filho, Lyoto, no $\mathrm{UFC}^{60}$, a maioria dos conceitos filosóficos e espirituais envolvidos na prática do Karate-Dō tomaram ar místico, quando são conhecimentos amplamente versados no oriente, servindo de base para inúmeras outras tradições e não apenas para as artes marciais.

Como explica-nos Blóise (2000), com quem BURKE (2008) parece concordar, as impressões no imaginário social sobre o oriente parecem extremamente místicas, mágicas e até sub intelectuais. Essa influência, provavelmente advinda dos filmes de ação e seriados de televisão ainda atrapalha nossa compreensão sobre a cultura dos japoneses, chineses e indianos, e faz o oriente parecer um lugar subdesenvolvido onde o ocidental pode manifestar certa superioridade mental e material. Além disso, a partir da década de 50, quando a arte começou a ser difundida, eram raros os livros sobre Karate e os que existiam muitas vezes não eram de qualidade ou estavam em idiomas que pouco se compreendia.

Outra ideia corrente precisa ser repensada: a de que o Karate (ou o próprio reino de Ryūkyū) se libertou de um Império Chinês dominador. Alguns autores costumam levantar a hipótese de que o Karate livrouse das garras chinesas através do trabalho do mestre Gichin Funakoshi, "por tê-lo modificado literal e filosoficamente de 'mãos chinesas', mãos do dominador, para 'mãos vazias', mãos de liberdade" (VIANNA, 1996). Convenhamos, no período em que Funakoshi viveu, nem o Karate era propriedade chinesa nem o Japão, que controlava a província de Okinawa, era dominado pela China, fazendo com que esta afirmação não se sustente.

Sabendo que Ryūkyū foi um Estado vassalo ao Império Chinês por muitos séculos, pagando tributos, mas também, recebendo inúmeras visitas (Sapposhi) que influenciaram a cultura local (especialmente a prática do Karate) essa relação não parece de dominação impositiva. Esta relação era, antes, encarada como vantajosa pelos membros da família Sho (realeza) e pelos Peichin (guerreiros). Através do intercâmbio cultural com a China, além de proteção militar 
contra naçôes mais poderosas, os Ryūkyū recebiam inúmeras visitas de especialistas em técnicas militares (Wushu), religião, arte, entre outros (OKINAWA, 2003). Essa forma de ver a influência estrangeira é também evidenciada pela fala do mestre Yasutsune Itosu descrita no livro de Gichin Funakoshi, Karate-Dō Nyūmon (1999), que diz ver com bons olhos a união da província de Okinawa com o Império Japonês. De fato Itosu vê, inclusive, como inevitável a participação dos oquinauenses na Guerra Russo-Japonesa, coisa que se concretizaria décadas depois (FunAKOSHI, 1999). Além disso, o período em que Ryūkyū foi um reino independente e vassalo da China foi marcado pelo maior desenvolvimento do Karate. É o período descrito como o de criação de manuscritos como o Bubishi, Kusanku-zaiko e outros, que eram copiados manualmente por praticamente todos os mestres das ilhas, como explicado anteriormente neste estudo.

Sendo assim, caímos no terrível problema do uso, nas décadas de 70 e 80 , principalmente, do termo Karate Jutsu. Entrando no embalo do Jiu Jitsu Brasileiro, técnica sistematizada pela família Greice através do conhecimento trazido pelo aluno de Jigorō Kanō, Mitsuyo Maeda, o Conde Koma (VIrGílio, 2002), alguns praticantes de um Karate mais prático (ou como assim o pensavam) também adotaram o termo Jutsu (grafia correta para o ideograma kanji que significa técnica) em detrimento do Dō.

No Japão, a partir da Restauração Meiji, que modernizou o país, diversas mudanças políticas e sociais ocorreram. Para o mundo das artes marciais, a fundação da Dai Nippon Butokukai ${ }^{61}$, uma instituição japonesa voltada para o desenvolvimento das artes marciais, foi um grande marco. A partir de seu estabelecimento, toda disciplina guerreira tinha que ser registrada nessa fundação e seguir certas normativas, como por exemplo, a adoção da graduação kyū/dan e o uso do dōgi branco. A partir desse registro a arte poderia ser reconhecida ou distinguida como Budō, desde que fosse uma antiga arte tradicional japonesa que antes se nomeava a partir do sufixo Jutsu. Como o Karate nunca foi uma arte tradicional japonesa e, portanto, não teve o sufixo Jutsu como parte de seu nome, nunca foi reconhecido como Budō (uma arte tradicional japonesa), apesar de ter sido reconhecida e registrada na Butokukai através dos esforços de Gichin Funakoshi (ANDRETTA, 2009; STEVENS, 2005).

Cabe lembrar também que todas as artes japonesas sem exceção sofreram mudanças neste período, abandonando os nomes antigos e adotando os novos juntamente das novas diretrizes e preceitos. Assim o Jūjutsu tornou-se Jūdō, o Kenjutsu tornou-se Kendō, o Kyūjutsu tornou-se Kyūdō e o Karate tornou-se Karate-Dō. Ou pelo menos a facção de mestres oquinauenses que seguiram Funakoshi no movimento de modernização e assim passaram a renomear também sua arte, sendo que ainda hoje existem em Okinawa estilos de Karate e até mesmo de Te (NAKAZATO et al., 2003; SHINJYO, SENAHA \& ONAGA, 2004). Isto também nos remete a não esquecermos que sob qualquer hipótese podemos considerar o Karate-Dō ou o Karate de Okinawa como disciplinas de luta originadas do Jūjutsu japonês, devido aos fatos aqui apresentados. Portanto, esta afirmação comum a muitos professores brasileiros também não se sustenta.

Karate é uma disciplina que nasce em Okinawa, quando a ilha fazia parte de um reino independente (Ryūkyū) e foi influenciada essencialmente pelo $W u$-shu chinês. A única lacuna que pode ser aberta a esse respeito é que o Wadō-ryū de Hironori Otsuka é uma mistura dos estilos de Jūjutsu que ele aprendeu na juventude com o Shōtōkan Karate-Dō, que estudou sob a tutela de Gichin Funakoshi, mas isso ocorreu no Japão em pleno século XX, quando a arte já possui algumas centenas de anos. Por estes e tantos motivos, o Karate não é uma "construção cultural tipicamente japonesa”, como já nos alertava o antropólogo Kevin TAN (2004).

Importa definirmos aqui uma significativa diferença: para os oquinauenses, Karate (ou simplesmente $T e$ ) é uma busca pela transcendência, pelo desenvolvimento espiritual, ou da Consciência, e pela sobrevivência (Ramos, 2001; SHInjyo, SEnaHa $\&$ OnaGA, 2004). Para os japoneses, Karate-Dō é uma busca pela formação do caráter, pela formação de um homem ético. O Karate de Okinawa se mostra muito ligado aos princípios taoistas e zen budistas. Este último é um sistema filosófico/religioso que é uma mistura de budismo (indiano) e taoismo (BLÓISE, 2000). Esta vertente se mostra muito ligada às técnicas divinatórias (BLóise, 2000), como os enraizamentos, respirações (ibuki) e uso da energia sutil para técnicas de defesa absoluta (STEVENs, 2001). Em contrapartida, o Karate-Dō foi muito influenciado pelo espirito samurai, um fenômeno tipicamente japonês, pois, como dito anteriormente, nasce a partir do ingresso no sistema Butokukai. Portanto, é uma arte que pretende estar ligada aos mesmos preceitos de outras formas de Budō japonês, onde o principal objetivo é construir um indivíduo útil para a sociedade, remetendo-nos à produção de corpos dóceis, conforme estudo de Michel Foucault (2000).

Há ainda os trabalhos que insistem em afirmar que Gichin Funakoshi era contrário às competiçōes. 
De fato o mestre era resistente à ideia de se praticar o Karate como uma exibição selvagem entre dois homens (NAKAYAMA, 2000), e poderia reprovar modalidades como as lutas de $\mathrm{MMA}^{62}$ contemporâneas. Porém não podemos afirmar que ele não compactuaria com um modelo competitivo do Karate como o atual modelo WKF. De fato o que os mestres não aceitavam era a prática do Shinken Shobu (duelo), que custou até mesmo a expulsão do principal discípulo de Jigōrō Kanō da Kodōkan, o talentoso Shiro Saigo. A própria saída de Masutatsu Oyama (o fundador do Kyokushinkaikan) do Shōtōkan foi devido a um desses combates onde o filho de Funakoshi, Gigo, teria sido derrotado por um karate-ka do estilo Gōjūryū (estilo que Oyama passou a praticar). Funakoshi tinha em mente um Karate que seguia os princípios do Budō, como citado anteriormente, da mesma forma que outras artes como Aikidō e Judô (onde se buscava o desenvolvimento equilibrado, como ser humano) do que com o antigo Jūjutsu (voltado apenas para os combates de guerra).

Pela amizade que mantinha com Morihei Ueshiba, Funakoshi parece compactuar com os princípios Masakatsu ${ }^{63}$ (vencer a si mesmo), Agatsu ${ }^{64}$ (vencer de forma justa, vencer pela ação) e Katsuhayari ${ }^{\text {65 }}$ (vencer pelo amor, encontrando a verdade universal) cultivados no Aikidō. Portanto, pensar que os antigos mestres eram contrários à competição esportiva organizada e provida de "fair-play" é um equivoco. $\mathrm{O}$ próprio Tanaka, um dos introdutores da arte no Brasil, afirma que a competição ajuda o praticante a desenvolver o equilíbrio emocional e o controle sobre o nervosismo (VianNA, 1996). De fato, Kenwa Mabuni, por ser descendente de uma família com título aristocrático guerreiro em Okinawa, estava mais preocupado com um Karate que fosse eficiente para a defesa pessoal do que para o desenvolvimento espiritual (Aguiar, 2008). Neste ponto, não há o que afirmar de diferente sobre Masutatsu Oyama, afinal sua fama internacional foi construída pela prática do Shinken Shobu, inclusive quando desafiou e venceu os lutadores tailandeses de Muay Thai, igualmente famosos e até então tratados como invencíveis.

Há ainda diversos problemas relacionados a aspectos próprios da cultura japonesa e de sua espiritualidade que confundem totalmente o praticante ocidental, talvez ainda mais o praticante brasileiro. Em nossa cultura acabamos dominados nos últimos 400 anos por um pensamento materialista e dualista, onde há uma cisão entre mente e corpo como entidades separadas. Como exemplificaram LAGE e GONÇALVES JUNIOR (2007), esse dualismo atrapalha os mestres japoneses estabelecidos no Brasil de explicarem aos seus estudantes que o Karate precisa ser vivenciado no cotidiano, levando à inteireza do Ser. Esse dualismo se opõe ao monismo das tradições orientais e dificulta a compreensão do conceito de energia vital pelo homem ocidental. Para o japonês, esse nível quântico intermediário da consciência, é chamado de $K_{i}{ }^{66}$ (Goswami, ReED \& GoswamI, 2008). Naturalmente, devido a todo um contexto cultural advindo do cartesianismo e do culto de uma alma ou mente separada do corpo, é muito difícil que compreendamos esse princípio, e até o ridicularizamos como crendice popular e misticismo (KUSHNER, 1988). De fato, a ciência de vanguarda está trabalhando para validar essa energia como parte de um campo físico que deve vir a ser chamado de Campo Akáshico ou Campo A. O problema desta falta de compreensão vem da mecanização de alguns exercícios, em especial ao Kiaijutsu ${ }^{67}$. Esta importante técnica muito desenvolvida pelos Bushi (RATti \& Westbrook, 2006) compreendia dois aspectos básicos, ambos representados com kanji diferentes, mas de mesma pronúncia. Em primeiro lugar, os guerreiros eram treinados em Kiai (presença espiritual) para aguçar a sensibilidade e a própria força de presença, podendo utilizar a intuição em combate. Em segundo lugar, transformavam a manifestação do campo vital (ou Campo Akáshico) em arma, somando o efeito desse campo ao golpe físico, que podia ser um soco ou chute, por exemplo, através de um brandido que conduzia a energia vital: o $\mathrm{Kiai}^{68}$ (grito de espírito). Infelizmente, o que vemos hoje é um costume de gritar de forma aleatória e sem consciência nas sessões de treinamento e nas competiçóes.

A visão de Funakoshi acerca destes conceitos de espiritualidade é tão importante para a compreensão do nome que reformula para a arte, que explica em sua obra que "acreditando com os budistas que é a vacuidade, o vazio, que jaz no coração de toda matéria, é a verdade de toda a criação" (FUNAKOSHI, 1999, p.47). Percebemos que as intuições dos antigos mestres sobre a natureza da realidade condizem com as conclusões dos pesquisadores de vanguarda, que vem afirmando que a realidade fundamental do universo é a consciência, ou, de forma análoga, o vácuo quântico (GosWAMI, ReEd \& GosWAMI, 2008; LASZlo, 2008). Essa ideia fundamentou toda a base psicopedagógica do trabalho de Funakoshi, tendo influenciado também professores que o seguiram (BArreira \& Massimi, 2003). Portanto, reduzir a conceituação de treinamento em Karate-Dō a uma espécie de treinamento para se executar o Kata ou simplesmente lutar através da prática do Kumite, 
é uma superficialidade em decorrência da incompreensão da filosofia oriental. Kata e Kumite são apenas partes do método para trilhar o Dō, ou seja, para unir-se ao Tao, à Totalidade, em um processo semelhante à individuação proposta pelos psicólogos junguianos e transpersonalistas.

É natural ouvir também dos professores antigos relatos em que se recordam de que, por mais que se esforçassem, não conseguiam ouvir um único elogio dos instrutores japoneses. Em autoanálise, sem conhecer a cultura que originou a própria arte, esses praticantes acabavam achando que se tratava de algum tipo de comportamento militar e que, portanto, nunca receberiam um elogio. Uma conclusão totalmente etnocêntrica. $\mathrm{O}$ que não compreendem é que, o que os japoneses provavelmente esperavam era a manifestação da atitude natural, o Zanshin, e da essência, o $R i$, enquanto observavam os brasileiros evoluindo cada vez mais a força física e a plástica performática, ambos os aspectos do modelo técnico rígido, o Ji (KusHNER, 1988). Esse quadro acabou resultando em inúmeras gerações de praticantes brasileiros que foram ofendidos, humilhados e até agredidos por professores que pensavam estar seguindo um modelo militar tipicamente japonês igual ao de seus mestres. Essa concepção está equivocada e o próprio mestre Funakoshi nos ajuda a

\section{Considerações finais}

Como vimos, a prática do Karate tem pouco ou nada a ver com o pensamento militar ou ligado a uma ideia de intervenção pedagógica liberal tradicional observada na atuação de muitos professores (LOPES \& TAVARES, 2008). Em primeira instância lembramos a própria organização tradicional dos praticantes num dōjō (o salão de prática e treinamento): enquanto que em artes voltadas a um aspecto militar, como a maioria das artes chinesas, em que os praticantes se organizam em fileiras atrás do professor (da mesma forma que os soldados se organizam nos pelotões) em um ambiente que reflete a matriz cultural japonesa a organização se dá em uma espécie de círculo (FIGURA 1). O sensei fica numa extremidade entendê-la e ressignificá-la com seus 20 princípios (muito popularizados pela internet como Niju Kun). A importância de $R i$ (essência) sobre $J i$ (técnica rígida) aparece principalmente nos ditos cinco: "o pensamento acima da técnica” (FunAKOSHI, 2005); e 17: "a Kamae (posição de prontidão) é para os iniciantes; com o tempo, adota-se Shizentai ${ }^{69}$ (postura natural)" (FunAKOSHI, 2005). Devido a essas más interpretações que o grande psiquiatra Carl Gustav Jung, fundador da psicologia analítica, tinha reservas sobre a prática ocidentalizada de atividades como a yoga: pensava ele que a essência podia se perder no processo de apropriação das tradiçõos e técnicas (BlóIse, 2000).

Obviamente, é uma opção dos professores brasileiros seguir ensinando um Karate no qual as instruções foram passadas por uma tradição oral que não teve o sucesso adequado pela falta de condiçóes dos imigrantes japoneses em se comunicar no idioma local e que, aparentemente mal interpretada, gerou a história de violência, especialmente nas décadas de 70 e 80, relatada pela mídia (Estilo, 1977). Porém, aqui, mostro uma inclinação para acreditar que o destemor (Mu-i em japonês) é atingido através de Katsuhayabi (estar pleno no Aqui e Agora) e não através da violência, assim, uma reflexão acerca do futuro se faz necessária.

(que podemos chamar de norte, a direção principal ou shomen), onde fica o kamiza (local elevado); os alunos adiantados ficam no leste, ou no jōseki, o assento superior; os praticantes novatos, por ordem de graduação vão se colocando na direção sul, de frente para o shomen, no shimoza, até ocupar o espaço da direção oeste, denominado shimozeki (BulL, 1988). Como pode uma prática que difere tanto do modelo militar e da educação liberal tradicional ter sido distorcida produzindo o Karate que vemos hoje? Espero ter apontado a maioria das razóes neste estudo, e que sirvam de reflexões para repensarmos, enquanto professores de Karate, de artes marciais e de Educação Física, nossa prática profissional. 
Fonte: acervo pessoal do autor.

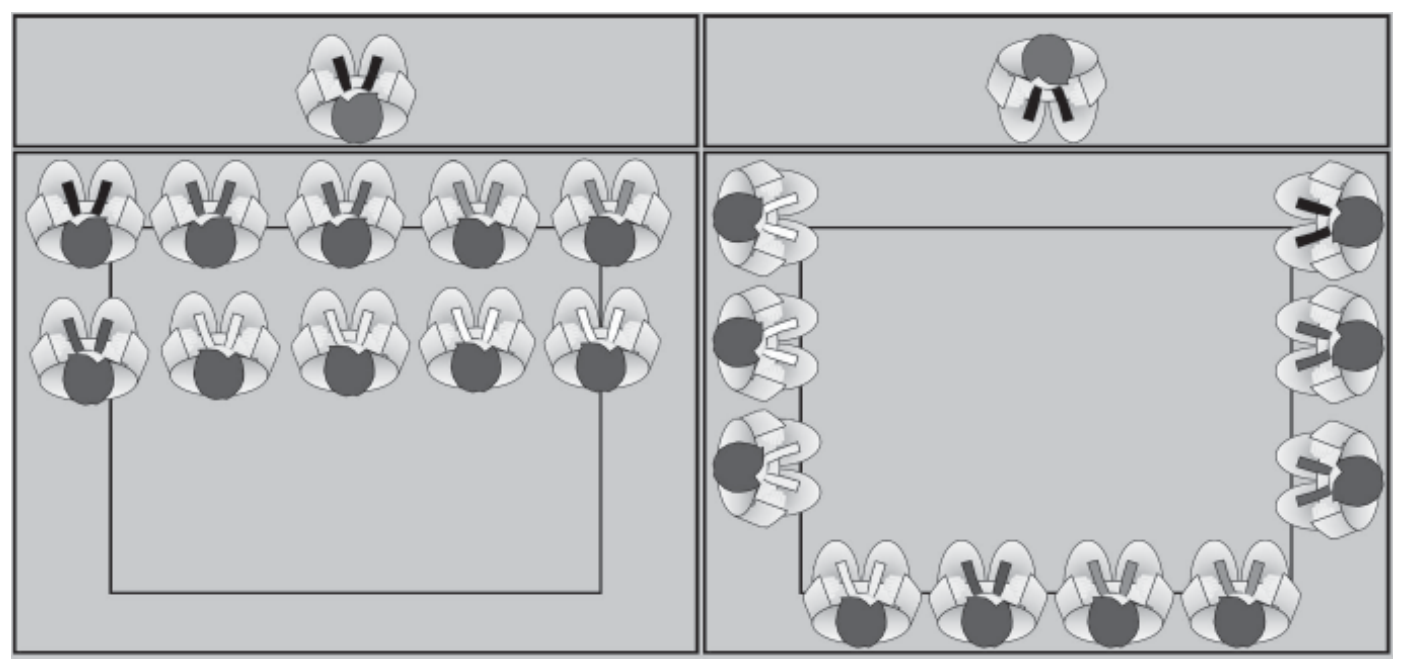

FIGURA 1 - Organização em fileiras típica da maioria das academias de $W u$-Shu (artes marciais chinesas), à esquerda, e organização espiralítica (círculo) seguindo a ordem de graduação do Budō (artes marciais japonesas) em sua forma mais tradicional, à direita.

O que não pode ser esquecido é que não há nada mais natural do que essa realidade que acabou resultando no Karate-Dō deste início de milênio. $\mathrm{O}$ processo de construção da própria sociedade humana aponta para a possibilidade de vermos os diversos fenômenos, dentre os quais as práticas esportivas ou atividades físicas não estão excluídas, percebendo as inúmeras relações caóticas nos diversos segmentos da cultura. Neste aspecto, o Karate é tema de meios e mídias, como o cinema, a televisão, revistas em quadrinhos, desenhos animados, livros, contos, caminhos de autoconhecimento e desenvolvimento pessoal (ou espiritual), do esporte aos jogos digitais (Frosi, 2009). Todos influenciando de alguma forma em cada uma das suas diferentes manifestações na construção de conceitos no imaginário social. Ao invés de nos preocuparmos em brigar por qual "Karate é o certo" chegou a hora de percebermos e apreciarmos esse fenômeno riquíssimo cultural e socialmente que é a arte das Mãos Vazias.

Há de se repudiar os inúmeros equívocos e práticas pedagógicas impróprias, e também rever a crítica à competição e à prática esportiva. Quando se pratica qualquer esporte com "fair-play", respeito, igualdade de condiçōes para a disputa e busca por desenvolvimento pessoal não existe nenhuma infração ao pensamento dos fundadores e idealizadores do Karate. Pelo contrário, a manifestação de respeito na competição, às regras, aos atletas adversários, aos árbitros e ao público não apenas mostram que o esporte pode ser diferente dos embates muitas vezes desleais que se estabelecem em outras práticas esportivas, como mostra que ele pode ser um verdadeiro caminho para o encontro com o Areté, a excelência humana descrita pelos filósofos gregos (Frosi, Oliveira \& Todt, 2008).

O caminho para a mudança é o estudo disciplinado, o manabu dos japoneses. Entender que o Karate não é um fenômeno cultural japonês, e sim o resultado de um processo influenciado por várias matrizes culturais, é necessário. É preciso conhecer a cultura, a religião, o idioma e, se possível, a própria metafísica que envolve uma prática corporal integrativa como o Karate-Dō. Assim poderemos realmente trilhar o Caminho do Guerreiro sem ocasionar nesse processo malefícios ao outro, a nós mesmos e ao nosso meio.

\section{Abstract}

\section{Rethinking the karate history spread in Brazil}

This study approaches several aspects of literature that shape the present thinking in the Brazilians imaginaries about the Karate-Dō identity, history and philosophy. The objective of this research is to produce a meta-analysis of the spread literature approaching is different styles. This study is justified by the fact of we consider that a distortion of Karate-Dō history was diffused in Brazil, by the media, 
oral tradition and preconception between some Karate-Dō styles practitioners. The reflections presented here seek contribute with information for another version's construction about this practice in Brazil.

UNITERMS: Karate; History, Sport.

\section{Notas}

1. [空手道] - Caminho das Mãos Vazias.

2. [柔術] - Técnica ou Arte Suave.

3. [菩提達磨] - Bodai Daruma, aquele que sustenta o Universo.

4. [少林] - Pequena floresta.

5. [琉球] - Universo; Antigo nome no arquipélago hoje conhecido como Prefeitura de Okinawa.

6. [沖縄] - Corda para o mar.

7. [平民] - Homem do povo, cidadão, plebeu.

8. [亲云上] - Título de nobreza dos guerreiros no reino de Ryūkyū.

9. [侍] - Aquele que serve (ao próximo), o termo que comumente designa os Bushi (guerreiros) e é oriundo do termo arcaico hirazamourai.

10. Atividades climáticas violentas, como as tempestades e chuvas torrenciais.

11. [手] - Mão.

12. [沖縄口] - Uchināguchi, idioma ou dialeto de Okinawa.

13. [島津氏] - Clã samurai do sul do Japão no período de 1600 d.C.

14. [唐手] - Mãos Chinesas.

15. [唐手] - Mãos Chinesas.

16. [冊封使] - (Cè Fēng Shǐ em chinês) - Emissário, embaixador, conferente.

17. [公相君].

18. [拳法] - (Quán-fă em chinês) - Método do Punho.

19. [公相君] - Oficial/Militar So.

20. [観空] - Contemplar o Céu.

21. [松村] - Fundador do Shuri-Te.

22. Um dos professores de Gichin Funakoshi especialista em Shuri-Te.

23. [東恩納] - Fundador do Naha-Te.

24. Misteriosa Mão Chinesa.

25. Miraculosa Mão Chinesa.

26. Técnica de brandido vocal para condução da energia vital, ou ki.

27. [義珍 船越] - Fundador do Shōtōkan.

28 [武術] - Técnica ou Arte Marcial, o mesmo que Bu-jutsu em japonês.

29 [首里手] - Mãos de Shuri.

30. [那覇手] - Mãos de Naha.

31. [泊手] - Mãos de Tomari.

32. [明治維新] - Meiji Ishin, movimento político que devolveu o poder ao Imperador do Japão, extinguindo o regime do Xogunato através do qual os Bushi governavam o país.

33. Na cultura chinesa e japonesa, ser versado na arte da caligrafia (shodō) era/é tão valoroso quanto ter habilidades em outros Caminhos como o Kendō, Jūdō, Kyudō, etc.

34. [柔道] - Caminho ou Via Suave.

35. [空手家] - Especialista em Karate.

36. [上着] - Parte de cima do Karategi [空手衣], casaco.

37. Calça-saia no estilo samurai.

38. [先生] - Aquele que nasceu antes, ancião, instrutor de Artes Marciais.

39. [唐手].

40. [空手]. 
41. [道] - Caminho ou Via.

42. [動衣] - Roupa de movimento, roupa de treino.

43. [朝基 本部] - Mestre de Shuri-Te e Tomari-Te.

44. Luta russa originada a partir das técnicas de Jū-Jutsu por professores japoneses no período anterior à Guerra Russojaponesa. Após a guerra a prática foi reinventada com o intuito de nacionalizá-la (VIrGílio, 2002).

45. [松濤館] - Academia de Shōtō (Funakoshi), Academia das Ondas de Pinheiros.

46. [剛柔流] - Estilo Suave e Forte.

47. [糸東流] - Estilo de Itosu e Higaonna.

48. [剣道] - Caminho da Espada, esgrima japonesa.

49. [治五郎 嘉納] - Fundador do Jūdō.

50. O fundador do Aikidō [合気道].

51. O fundador do estilo Wadō-ryū [和道流].

52. O filho mais velho de Gichin Funakoshi e braço direito no ensino e difusão do Karate do Shōtōkan Dōjō.

53. A influência dos clubes universitários japoneses foi pouco importante na introdução do Karate no Brasil, que se deu inicialmente por imigrantes que se estabeleceram na colônia do Estado de São Paulo. A influência dos membros destes clubes faz parte do imaginário compartilhado pelos praticantes do "Karate Tradicional", mas é de um período posterior.

54. Escola da Verdade Definitiva.

55. [氏] - Clã, para os guerreiros japoneses.

56. [残心] - Atitude natural.

57. [道] - Geralmente traduzido por Caminho, Dō significa Totalidade, em chinês é pronunciado Tao ou Dao. Portanto, as inúmeras disciplinas marciais orientais se caracterizam como caminhos para a Totalidade, para a transcendência, holopráxis.

58. [腹] - Abdome ou centro de poder, cujo ponto central, o saika tanden [最下丹田], é considerado o local onde as reservas de Energia Vital se acumulam no ser humano.

59. [無心] - Mente liberta, vazia.

60. Ultimate Fighting Championship, um dos maiores eventos de "Artes Marciais Mistas" da atualidade.

61. [大日本武徳会] - Associação das Virtudes Militares do Grande Japão.

62. Mixed Martial Arts/Artes Marciais Mistas, popularmente conhecidas como "vale-tudo".

63. [正勝].

64. [吾勝].

65. [勝早日].

66. [氣] - Energia vital, energia ou in-formação do nível vital/emocional da Consciência. Na sua grafia tradicional mais conhecida é uma imagem do vapor (气) subindo do arroz (米) enquanto cozinha, ou seja, o movimento entre o denso (arroz, material) e o sutil (vapor, transcendente).

67. [氣合術] - Técnica de concentração da Energia Vital.

68. [氣合] - Reunir/concentrar a energia vital.

69. [自然体] - Postura natural.

\section{Referências}

AGUIAR, J. Karatê Shito-ryu: os grandes mestres, os katas, entrevistas. São Paulo: Geográfica, 2008.

ANDRETTA, D.A.C. Manabu no Karate-Dō. 2009. Disponível em: <htttp://www.manabunokaratedo.esporteblog. com.br>. Acesso em: 7 jul. 2009.

AUGUSTO, J. Koryu e Gendai Budo: reflexão. Disponível em: www.bugei.com.br/ensaios/. Acesso em: 15 mai. 2009. (Portal da Sociedade Brasileira de Bugei).

BARREIRA, C.R.A.; MASSIMI, M. As idéias psicopedagógicas e a espiritualidade no Karate-Do segundo a obra de Gichin Funakoshi. Psicologia: Reflexão e Crítica, Porto Alegre, v.16, n.2, p.379-88, 2003.

BARTOLO, P. Karate-Do: história geral e do Brasil. Santos: Realejo, 2009.

BLÓISE, P.V. O Tao e a psicologia. São Paulo: Angra, 2000.

BÜLL, W.J. Aikido: o caminho da sabedoria. São Paulo: DAG, 1988.

BURKE, P. O que é história cultural. Rio de Janeiro: Jorge Zohar, 2008.

310 • Rev. bras. Educ. Fís. Esporte, São Paulo, v.25, n.2, p.297-312, abr./jun. 2011 
CAMPS, H.; CEREZO, S. Estudio técnico comparado de los katas de karate. Barcelona: Editorial Alas, 2005. CONFEDERAÇÃO BRASILEIRA DE KARATE (CBK). História do karate. São Paulo: 2004. Disponível em: <www. karatedobrasil.org.br>. Acesso em: 13 mai. 2009.

. Biografia de Yoshihide Shinzato. Revista Digital Karate-Do On-line, São Paulo. Disponível em: <www.karateonline.com.br>. Acesso em: 08 fev. 2007.

CHAMBERS, J.; DUFF, B. Human weapon: karate. History Channel. AETN, 2008.1 DVD-ROM.

EGAMI, S. The Heart of Karate-Dō. Tóquio: Kodansha Intenational, 2000.

ESPERANÇA olímpica: karate. Veja, São Paulo, n.1806, p.122, 11 jun. 2003. Disponível em: <http://acervoveja.digitalpages.com.br/>. Acesso em 14 abr. 2009.

ESTILOS de luta: karate. Veja, São Paulo, n.454, p.88-90, 18 maio 1977. Disponível em: <http://acervoveja.digitalpages. com.br/>. Acesso em 14 abr. 2009.

FOUCAULT, M. Vigiar e punir. Petrópolis: Vozes, 2000.

FROSI, T.O. Os reis da luta: representações do karate nos jogos digitais. Monografia (Curso de Graduação em Educação Física - Bacharelado) -UFRGS, Porto Alegre, 2009. Disponível em: <http://www.lume.ufrgs.br>.

FROSI, T.O.; OLIVEIRA, G.B.; TODT, N.S. Budô e olimpismo: a confluência de símbolos do oriente e do ocidente na busca de valores para a sociedade moderna. Corpo em Movimento, Canoas, v.6, n.1, p.103-21, 2008.

FUNAKOSHI, G. Karatê-Dō: meu modo de vida. São Paulo: Cultrix, 2000.

. Karatê-Do Kyōhan: the master text. Tokio: Kodansha International, 1973.

Karatê-Do Nyūmon: texto introdutório do mestre. São Paulo: Cultrix, 1999.

Os vinte princípios fundamentais do karatê: o legado espiritual do mestre. São Paulo: Cultrix, 2005.

GAYA, A. (Org.) Ciências do movimento humano: introdução à metodologia da pesquisa. Porto Alegre: Artmed, 2008. GONELLA, R. Do, viaggio attraverso il karate alla ricerca dell'antico To-De. [S.l: s.n.], 2003.

GOULART, J. Portal judô fórum. Disponível em: <http://judoforum.com/blog/joseverson/. Acesso em: 15 jul. 2009.

GOSWAMI, A.; REED, R.E.; GOSWAMI, M. O universo autoconsciente: como a consciência cria o mundo material. São Paulo: Aleph, 2008.

HIGAONNA, M. Traditional Karatedō Okinawa Gōjū-ryū: performances of the kata. Tokio: Minamato Researchs, 1986. v.2.

JAPAN KARATE-DŌ FEDERATION (JKF). Karate-Dō Kata Kyōhan Shitei Kata: Kata Model for Teaching. Tóquio: Japan Karate-Dō Federation, 2008.

KNIGHT, C.; LOMAS, R. A máquina de Uriel: as antigas origens da ciência. São Paulo: Madras, 2006.

KUSHNER, K. O arqueiro Zen e a arte de viver: uma flecha, uma vida. São Paulo: Pensamento, 1988.

LAGE, V.; GONÇALVES JUNIOR, L. Karatê-Do como própria vida. Motriz, Rio Claro, v.13 n.1, p.33-42, 2007.

LASZLO, E. A ciência e o campo akáshico: uma teoria integral de tudo. São Paulo: Cultrix, 2008.

LOPES, Y.M.; TAVARES, O.G. A prática pedagógica dos mestres de caratê da Grande Vitória (ES). Pensar a Prática, Goiânia, v.11, n.1, p.91-7, 2008.

LOWE, B. Mas Oyama's karate: cómo se enseña en el Japón. Buenos Aires: Editorial Glem, 1967.

MACAN, J.; BUNDALO-VRBANAC, D.; ROMI'C, G. Effects of the new karate rules on the incidence and distribution of injuries. British Journal of Sports Medicine, London, v.40, p.326-30, 2006.

NAKAYAMA, M. Karatê dinâmico. São Paulo: Cultrix, 2004.

. O melhor do karatê: visão abrangente - práticas. São Paulo: Cultrix, 2000. v.1.

NAKAZATO, J.; OSHIRO, N.; MIYAGI, T.; TUHA, K.; KOHAGURA, Y.; HIGAONNA, M.; TAIRA, A.; SAKUMOTO, T. Okinawa karate and martial arts with weaponry. Okinawa: 2003. Disponível em: <www.wonder-okinawa. jp/023/eng>. Acesso em: 20 jun. 2005.

OKINAWA. Prefecture. Okinawa Digital Archives: Wonder Okinawa. Okinawa: 2003. Disponível em: <www.wonderokinawa.jp/>. Acesso em: 4 mar. 2009.

OLIVEIRA, E.F.; MILLEN NETO, A.; JORDĀO, T. Karatê. In: DACOSTA, L. (Org.). Atlas do esporte no Brasil. Rio de Janeiro: Shape, 2005.

OYAMA, M. Mas Oyama's essential karate. New York: Sterling, 1980.

PARANHOS, W. Nuvens cristalinas em luar de prata. Porto Alegre: FEEU, 1994.

PESAVENTO, S. História \& história cultural. 2. ed. Belo Horizonte: Autêntica, 2008.

PETTINI, R.L. Karate Kyokushin Oyama: uma visão geral. Monografia (Graduação - Licenciatura em Educação Física) - Escola de Educação Física, Universidade Federal do Rio Grande do Sul, Porto Alegre, 2005. 
RAMOS, A.J.C. Efeito do treino de Karate-Do Okinawa Goju-ryu nos conteúdos da consciência. 2001.214 p. Dissertação (Mestrado) - Faculdade de Motricidade Humana, Universidade Técnica de Lisboa, Lisboa, 2001.

RATTI, O.; WESTBROOK, A. Segredos dos samurais: as artes marciais do Japão feudal. São Paulo: Madras, 2006. REID, H.; CROUCHER, M. O caminho do guerreiro: o paradoxo das artes marciais. São Paulo: Cultrix, 2004.

ROSS, T. Choki Motobu: through the myth...to the man. Disponível em: <http://www.fightingarts.com/>. Acesso em: 15 mai. 2009,

RYŪSAKU, T.; BERRY, W.M.T.; KEENE, D. Sources of Japanese tradition. New York: Columbia University, 1964. SHINJYO, K.; SENAHA, S.; ONAGA,Y. Three major schools of Okinawa karate. Lake Forest: YOE, 2004. 2 DVD-ROM. SHINZATO, Y.; BUENO, F.A. Kobu-Do: as armas antigas de Okinawa. São Paulo: On-line, 2007.

STEVENS, J. Três mestres do budô: Kano, Funakoshi, Ueshiba. São Paulo: Cultrix, 2005.

STEVENS, J. (Org.). Segredos do budô. São Paulo: Cultrix, 2001.

TAN, K.S.Y. Constructing a martial tradition: rethinking a popular history of Karate-Dou. Journal of Sport and Social Issues, Thousand Oaks, v.28, n.169, p.169-92, 2004.

TAZAWA, Y. História cultural do Japão: uma perspectiva. São Paulo: Ministério dos Negócios Estrangeiros, 1980.

TOGUCHI, S. Okinawan Goju-ryu: fundamentals of Shorei-kan Karate. Burbank: Ohara, 1976.

VIANA, J.A. Valores tradicionais do karate: uma aproximação histórica e interpretativa. In: RODRIGUES, M.A.A. et al. (Orgs.). Coletânea do IV Encontro Nacional de História do Esporte, Lazer e Educação Física. Belo Horizonte: UFMG/EEF, 1996. p.552-60.

VIRGÍLIO, S. Conde Koma: o invencível yondan da história. Campinas: Átomo, 2002

WORLD KARATE FEDERATION (WKF). Disponível em: <http://www.karateworld.org/>. Acesso em 26 nov. 2007. YAMASHIRO, J. Okinawa: uma ponte para o mundo. São Paulo: Cultura Editores Associados, 1993.

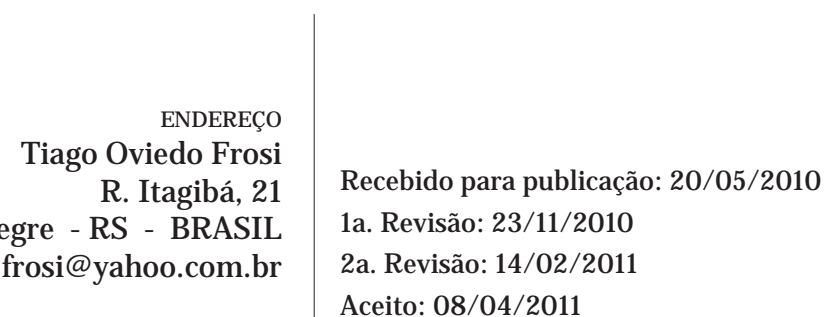

Aceito: 08/04/2011 